\title{
EPIPHANY OF RATNA INDRASWARI IBRAHIM AS AUTHOR
}

\author{
Susilo Mansurudin
}

\section{Universitas Islam Negeri Maliki Malang}

\begin{abstract}
Abstrack: Epiphany is a crucial event encountered by an individual which gives him/her an insight in his/her journey of meaning making to life. This qualitative research aims at finding out epiphany of RII represented in her anthology of short stories, novelets, novels. The research has found out that RII, as a diffable figure, is mentally capable of creating extraordinary works which are: (a) useful for others, (b) inspiring, (c) affecting surrounding people to be stronger, and (d) mostly true-story based. As a writer, RII's epiphany covers three main issues, i.e. (i) humanity epiphany, (ii) femininity epiphany, and (iii) diffability epiphany.
\end{abstract}

Keywords: epiphany, writer, diffability

\begin{abstract}
Abstrak: Epiphany merupakan peristiwa besar dari seseorang (individu) yang berwujud pencerahan dalam perjalanan pemaknaan kehidupan. Penelitian kualitatif ini bertujuan untuk mengetahaui epiphany penulis Ratna Indraswari Ibrahim (RII). Data penelitian berupa antologi cerpen, novelet, dan novel RII, maupun dokumen-dokumen penting tentang RII. Hasil penelitian menunjukkan sebagai sosok difabel, RII secara mental mampu menghasilkan karya yang luar biasa: (a) bermanfaat bagi publik, (b) mampu menginspirasi, (c) mampu mengubah orang-orang sekitar menjadi lebih berdaya, dan (d) sebagian besar karya RII dihasilkan berdasarkan kisah nyata. Epiphany RII sebagai pengarang terdapat tiga hal utama, yakni (i) epiphany kehumanisan, (ii) epiphany kefeminisan, dan (iii) epiphany kedifabelan.
\end{abstract}

Kata kunci: epiphany, pengarang, dan kedifabelan

Pengarang tidak dapat lepas dari memori, imajinasi, peristiwa yang melingkupi dalam alam realitas. Kehidupan nyata merupakan pengalaman yang menjadi modal dalam menunjang ekspresi kepengarangan. Semakin banyak pengalaman, pemikiran (pandangan dunia), turut serta memengaruhi kekaryaannya. Ratna Indraswari Ibrahim (selanjutnya disingkat RII) termasuk pengarang yang tidak dapat lepas dari kekuatan zamannya. Sebagai pengarang ia mengalami peristiwa-peristiwa penting dalam kehidupannya. Pengalaman yang ia dapatkan tidak serta-merta langsung mengubah jalan kehidupannya. Ada proses dalam menjalani kehidupannya sebagai pengarang. 
RII mampu melakukan perubahan yang mendasar dalam kehidupannya. Perubahan mendasar sebagai pengarang merupakan titik tolak untuk mengubah kehidupannya. Perubahan hakiki RII adalah mampu membangun dan mengartikulasikan kehidupan difabel menjadi manusia yang berguna, bermanfaat serta menginspirasi masyarakat secara luas. Perubahan yang dilakukan ini termasuk dalam terminologi epiphany.

Epiphany RII bukan merupakan rekayasa, tetapi karena keadaan yang membuat dirinya harus berbuat lebih baik dan berguna dalam kehidupannya. Citra diri sebagai difabel tidak menyurutkan untuk melakukan pergeseran paradigma dan memberikan manfaat untuk masyarakat, bangsa, dan negara. Creswell (2007:55) memaknai epiphany sebagai keunikan identitas subjek; adanya lompatan peristiwa penting sebagai titik tolak terhadap pemaknaan kehidupan. Pernyataan Creswell sama dengan apa yang dikemukakan oleh Denzin (1989:71) bahwa epiphany atau turning point moment merupakan pengalaman menarik yang sangat memengaruhi atau mengubah hidup seseorang.

Penelitian terdahulu yang berhubungan dengan epiphany masih belum banyak dilakukan. Disertasi mengenai epiphany pernah dilakukan oleh McDonald dengan judul Epiphanies: An Existential Philosophical and Psychological Inquiry tahun 2005 di Pascasarjana Universitas Teknologi, Sydney.

Kajian mengenai keunikan RII sebagai pengarang menjadi menarik dan penting untuk ditelaah karena didasarkan pada dua hal, yakni (i) melalui hakikat peristiwa pengarang, dan (ii) pengarang karya sastra itu sendiri. Artinya, epiphany menyertai diri pengarang dalam perjalanan kehidupan secara faktual, nyata, dan sebagai titik tolak perubahan mendasar perjalanan hidup seseorang. Dasar pemikiran dan pertimbangan tersebut melatarbelakangi perlunya mengkaji dan meneliti epiphany RII sebagai pengarang sastra. Dengan demikian, tujuan yang hendak dicapai dalam penelitian ini adalah mengungkap epiphany RII sebagai pengarang dilihat dari sisi kehumanisan, kefeminisan, dan kedifabelan.

\section{METODE}

Data dalam penelitian ini berupa unit-unit verbal teks yang dikutip dari karya sastra (cerpen, novelet, novel) yang ditulis RII, baik berupa dialog, monolog, narasi, maupun deskripsi. Sumber data meliputi naskah sastra, informan, dokumen, baik berupa dokumen keluarga, maupun pembirataan tentang RII di media massa. Peneliti sebagai instrumen penelitian dibekali sejumlah instrumen gambar. Teknik analisis data meliputi kegiatan reduksi data, penyajian data, dan penarikan kesimpulan sesuai dengan model interaktif Miles dan Huberman (1992:20). Pengecekan keabsahan data dilakukan dengan triangulasi, yakni triangulasi sumber, metode, dan teori.

\section{HASIL DAN PEMBAHASAN}

\section{Hasil Penelitian}

\section{Peristiwa Penting yang secara Internal dialami RII dan Berpengaruh pada Proses Penulisan}

Pemahaman terhadap seseorang tidak harus melalui seseorang itu sendiri. Seorang peneliti dapat memahami, mengetahui, dan mengenal seseorang dengan melalui media maupun sumber lain. Paham inilah yang disebut sebagai solipsisme (Fay, 2002: 1-34). 
Untuk mengetahui, mengenal, memahami kehendak, niat, motivasi maupun alasan-alasan RII menjadi pengarang dapat diketahui dari pihak-pihak lain maupun sumber lain. Demikian pula alasan-alasan yang terkandung dalam diri RII ketika menjadi pengarang dapat diketahui, dikenali, dan dipahami dari sumber di luar RII.

Bersastra merupakan satu-satunya jalan bagi RII dalam memberikan berbagai kemungkinan di antara segala aktivitas fisik yang lain. Sejak awal RII bercita-cita menjadi ahli akuntansi maupun ahli psikologi, tetapi diurungkan niatnya karena menyadari masyarakat Indonesia masih takjub dengan hal yang sifatnya visual. RII merasa akan diremehkan jika bekerja di wilayah publik, maka dirinya memutuskan menjadi pengarang, seperti ungkapannya berikut ini.

"Aku urungkan niat itu karena secara visual mungkin aku diremehkan. Maka aku memutuskan menjadi pengarang...," kata Ratna. (Kompas, 16 Mei 2010)

RII tidak mau diperlakukan sebagai seseorang yang istimewa meski dirinya mempunyai keterbatasan. RII mempunyai prinsip tidak mau tergantung pada orang lain, orang-orang sekitar, dan keluarga terdekat. Bukti dirinya tidak tergantung pada orang lain, RII mempunyai banyak prestasi. Meski difabel, RII meraih beberapa penghargaan di bidang sastra dan feminisme. RII dikenal sebagai pribadi yang produktif dan memiliki energi kreatif yang besar dalam berkarya sastra dan dunia kepengarangan. Sejak 1977 dia aktif menjadi ketua Yayasan Bhakti Nurani Malang, Disable Person Organization, sebagai Direktur I LSM Entropic Malang (1991). RII mendapat kesempatan mengikuti berbagai seminar internasional, seperti Disable People International di Sydney (1993), Kongres Internasional Perempuan di Beijing (1995), Leadership Training MIUSA di Eugene Oregon USA (1997), Kongres Perempuan Sedunia di Washington DC (1997), serta pernah mendapat predikat wanita berprestasi dari Pemerintah RI (1994).

Dari berbagai peristiwa penting yang dialami RII dapat disimpulkan bahwa epiphany RII dapat berasal dari dalam diri RII maupun dari luar. Dari dalam diri RII berupa peristiwa besar, yakni kesadaran diri RII sebagai difabel, sedangkan dari luar adalah berupa karya sastra RII, yakni berupa tulisan cerpen, novelet, dan novel.

Pilihan RII menjadi pengarang karena alasan berikut. Pertama, RII menahbiskan diri terjun dalam karya sastra karena dalam sastra tidak ada diskriminasi dalam hal imajinasi atau tulisan. Satu-satunya yang bisa diterima tanpa diskriminasi adalah tulisan. Kedua, melalui dunia sastra, pikiran-pikiran, pandangan menjadi lebih bebas tanpa adanya sekat dalam berekspresi. Ketiga, dunia sastra (karang-mengarang) sebagai satu-satunya hal yang dapat dilakukan oleh RII karena keterbatasan fisikal.

Dunia sastra merupakan satu-satunya pilihan RII dalam bekerja, berkarya, dan mengekspresikan diri, membantu orang lain, menginspirasi khalayak selalu bersikap yang lurus dan baik, bermanfaat sekaligus menyenangkan (dulce et utile). Sastra memiliki nilai estetis berupa kesatuan dalam keberagaman, distansi estetis, penciptaan kerangka seni, ciptaan, imajinasi, dan kreasi (Horatius dalam Teeuw, 1984:183). Bahkan Saryono (2009: 202-219), menyatakan bahwa sastra tidak hanya menghidangkan pengalaman, pengetahuan, dan kesadaran, tetapi juga hiburan karena sastra jenis apa pun (puisi, fiksi, dan drama) yang digubah secara jujur dan sungguh-sungguh selalu memancarkan sinyal permainan yang menyenangkan. 


\section{Peristiwa Penting yang secara Eksternal Dialami RII}

RII mempunyai pertimbangan eksternal dalam menekuni dan menggeluti dunia sastra. Selain alasan dari dalam diri pribadi, RII juga mempunyai alasan di luar pribadinya. Ada beberapa peristiwa penting yang dialami oleh RII ketika menjalani kehidupan sebagai awal menjadi pengarang.

RII pernah menolak akan keberadaan Tuhan. Hal ini dipicu oleh perasaan RII tentang kelima saudaranya yang begitu sempurna dan cantik, sementara dirinya dalam kondisi difabel. Menulis bagi RII adalah menginspirasi. Bagi RII menulis hanyalah salah satu kegiatan, tapi berbuat nyata dan menginspirasi orang lain adalah 'tugas besar' yang terus ditunaikannya semasa hidup, sekalipun dari atas kursi roda.

RII membutuhkan aktualisasi diri sebagai makhluk sosial dan makhluk berkebutuhan. RII mempunyai alasan RII beraktualisasi diri dan memenuhi kehidupan sosialnya. Jalan yang ditempuh RII adalah harus mengarang.

\section{Pandangan RII terhadap Tugas Besar Besar Sastrawan}

Melalui karya sastranya RII mempunyai tanggungjawab melawan ketidaksewenangwenangan, melawan ketidakadilan, membela perempuan dsb. RII konsisten membela kaum perempuan melalui karyanya; Lemah Tanjung (2003), Pecinan Kota Malang (2008), 1998 (2012), Kalibakar (2007) Aminah di Suatu Hari (2004), Bunga Kopi (2008), Gambarnya Sumi (2009).

Hasil karya berupa cerpen, novelet, dan novel dapat dirangkum sebagai upaya keras tugas besar RII sebagai sastrawan. Tugas besarnya adalah membaca dan menulis karya sastra yang bermanfaat, berupa (1) membawa amanat kebaikan kepada pembaca, penikmat sastra, pemerhati sastra maupun kritikus sastra; (2) memberikan informasi kepada publik tentang arti dan makna kehidupan yang sering tidak terjangkau dalam kehidupan nyata; (3) memberikan pandangan dunia yang tidak memihak pada satu kepentingan apapun karena kepentingan yang diemban adalah sebagai manusia yang sesuai dengan hati nurani kebenaran; (4) kepada publik, pembaca sastra, penikmat sastra diajak mengambil hikmah atas karya sastranya.

\section{Mengarang sebagai Strategi Perjuangan}

Karya sastra dapat dijadikan strategi perjuangan dalam melawan kesewenangwenangan, ketidakadilan maupun sistem yang selalu menguntungkan pihak tertentu. RII menyadari sebagai Arema (nita) mempunyai tanggung jawab yang besar terhadap keberlangsungan keharmonisan, kelestarian kehidupan lingkungan hidup, maupun terjaminnya tata hijau dan kesegaran iklim di Malang, seperti yang pernah dituturkan.

"Sungguh, karena saya Arema (Arek Malang), saya enggak rela Lemah Tanjung hilang. Saya sangat sedih. Makanya, liku-liku hidup, cinta, dan nafas perlawanan dalam novel LemahTanjung sedemikian kuat dan gampang terbaca. Saya melawan tidak secara fisik, tapi lewat sastra."

Protes perempuan yang pro-Lemah Tanjung merupakan penolakan rakyat, perempuan yang tak punya kuasa dan marah karena pengabaian (terus dibangun real estate). Gerakan RII sering dianggap sebagai gerakan politik yang kecil, lokal, sporadis, ternyata merupakan rangkaian gerakan perempuan global yang punya banyak kesamaan yangterjadi di berbagai belahan dunia. Perlawanan RII melalui karya sastra (Kalibakar, Lemah Tanjung, 1998) 
merupakan gerakan perlawanan perempuan lokal melawan imperalisme "baru"; gerakan perempuan seluruh dunia yang berhadapan dengan kekuatan global.

Perlawanan RII terhadap segala fenomena ketidakadilan ditunjukkan dalam bentuk karya sastra. RII melawan bukan dengan cara-cara yang anarkis, terbuka, namun dengan cara halus yang memberikan dampak pada kesadaran terhadap mental seseorang.

\section{Pembahasan}

\section{Epiphany Kefeminisan RII menjadi Pengarang}

Teori Wallas dalam bukunya The Art of Thought (Piirto, 1992 dalam Munandar, 58-50) menyatakan bahwa proses kreatif meliputi empat tahap, yaitu (1) persiapan, (2) inkubasi, (3) iluminasi, dan (4) verifikasi. Sementara dalam Sigmund Freud (1900) proses kreatif (proses terciptanya) karya sastra berupa dua hal, melalui sublimasi dan asosiasi. Proses kreatif RII dapat dikatagorikan dalam tiga hal utama sebagai patokan (1) proses penulisan, (2) proses pengungkapan gagasan, dan (3) proses pematangan gagasan.

RII mengakui memang dilahirkan bukan sebagai seorang penulis atau pengarang, namun kemampuannya menulis karena ia melakukan (menulis) dan belajar terus sampai akhirnya sering disebut sebagai sastrawan, bukan sastrawati. Lingkungan keluarga Ibrahimlah yang turut andil besar dalam membentuk karakter dan mengarahkan RII sebagai penulis dan pengarang. Selebihnya adalah RII belajar mandiri dengan para satrawan terdahulu, mulai Sapardi Joko Damono, WS Rendra, Ken Yuraida, Emha Ainun Najib, Umbu Lumbu, dsb.

Proses menjadi penulis pun tidak dengan mudah dilalui RII. Berbagai latihan dan berkirim karya fiksi ke surat kabar lokal dilakukan. Ketika RII memenangkan sayembara di Bali Post, dirinya menjadi percaya diri dan mantap untuk menahbiskan dirinya bekerja, berekspresi, dan berkarya dalam dunia tulis-menulis, khususnya karya sastra.

Proses menulis dan dicetaknya hasil kumpulan cerpen sebagai antologi pun tak mudah. Berkali-kali kumpulan karya RII ditawarkan kepada penerbit untuk dibukukan, namun berkali-kali pula ditolaknya. RII tak berputus asa, meskipun butuh proses pengakuan yang begitu panjang. Penulis lain pun ketika mau menerbitkan pun juga berkali-kali ditolak.

RII tidak mempunyai jam khusus ketika mencari mood, ilham ataupun gagasan ketika akan mengarang. Bagi RII menulis bisa kapan saja dan di mana saja asalkan ada yang mendampinginya (pengetik). Pada siang hari RII bisa menulis maupun malam hari. Akan tetapi, jika menulis siang hari banyak tamu yang berkunjung ke rumah sehingga proses penulisan terhenti. Malam pun juga banyak tamu sehingga karyanya terkadang tak bisa cepat diselesaikan.

Tamu yang datang ke rumah di Jalan Diponegoro nomor 3 Malang tersebut bagi RII dianggap sebagai informan. Meski terkesan tamu datang akan menganggu penyelasaian akhir penulisan RII, namun sebaliknya tamu yang datang menjadi sumber informasi, sumber pemecahan masalah, sumber lancarnya penulisan RII. Hal ini dikarenakan RII membutuhkan banyak teman untuk berbincang, berdiskusi, menerima keluh kesah, curahan hati. Hasil pembicaraan tersebut merupakan bahan dan materi untuk keperluan dalam mengarang.

Munculnya novel Pecinan Kota Malang (2008) sebenarnya dari keluh kesah dan curhat tamu yang tak dikenal RII. Ada tamu etnis Tionghoa mengalami persoalan pribadi, kemudian mencurahkan semua isi hatinya sebagai etnis Tionghoa yang merasa kurang 
mendapat porsi sama dengan etnis lainnya, maka RII kemudian membuat karya dengan tema kemajemukan. Selanjutnya RII mencari informasi, bertanya secara lisan kepada teman-teman, sahabat, dan mencari buku berkaitan dengan etnis Tionghoa.

RII tidak mempunyai target khusus dalam menyelesaikan cerpen, novelet maupun novel yang dikerjakannya. Semua dibiarkan mengalir laiknya seperti air. Awalnya membuat sinopsis cerita, kerangka yang konstruktif, dan runtut alurnya. Jika sinopsis perlu pengembangan ia diskusikan dengan para asisten yang membantunya menulis agar ceritanya tidak rancu. RII dalam menulis memang luar biasa, berbeda dengan orang lain. Bila orang lain menggunakan kerangka karangan (outline), RII cukup berbicara dan ada pengetiknya

Masyarakat diajak untuk merekonstruksi nilai-nilai sebelumnya yang semula memandang kondisi cacat atau tidak normal sebagai kekurangan atau ketidakmampuan menjadi pemahaman terhadap difabel sebagai manusia dengan kondisi fisik berbeda yang mampu melakukan aktivitas dengan cara dan pencapaian yang berbeda pula. Dengan pemahaman baru itu masyarakat diharapkan tidak lagi memandang para difabel sebagai manusia yang hanya memiliki kekurangan dan ketidakmampuan. Sebaliknya, para difabel sebagaimana layaknya manusia umumnya, juga memiliki potensi dan sikap positif terhadap lingkungannya.

RII tidak melakukan ritual khusus dalam menyelesaikan karya sastranya. Sebagian sastrawan masih banyak yang melakukan ritual khusus, misalnya dapat menuangkan gagasan jika di kamar mandi, harus mandi kembang, bersujud, bermeditasi atau bertapa, berpuasa, dst. Beberapa pengarang dapat menulis ketika melakukan kegiatan tertentu. Arswendo Atmowiloto suka berpetualang untuk memperoleh bahan tulisannya. Nh. Dini harus meminta izin keluarganya ketika akan menulis karya sastra. Bagi Nh. Dini ketika menulis tidak boleh ada gangguan siapapun termasuk keluarganya. Ahmad Tohari dapat menulis ketika dirinya mengalami 'hamil sastra'. A.A. Navis dapat berkarya kalau banyak membaca buku atau karya sastra orang lain, melihat film, mendengar cerita, dan mengamati tingkah laku orang sekitarnya. Linus Suryadi dapat menulis Pengakuan Pariyem karena tertantang untuk menulis puisi yang panjang (Eneste, 2009)

RII dapat menyelesaikan novel Lemah Tanjung (2003) seiring proses pengalihan fungsi hutan kota juga selesai. Novel Lemah Tanjung (2003) ditulis mengikuti perkembangan pengalihan fungsi hutan kota menjadi perumahan mewah. Sebelum menjadi novel dan diterbitkan, cerita Lemah Tanjung dimuat sebagai cerita bersambung di Jawa Pos. Ketika selesai dan diterbitkan menjadi novel dengan judul Lemah Tanjung (2003) beberapa hari kemudian novel tersebut hilang dari beberapa toko buku. Hilangnya novel tersebut dari peredaran akibat cerita tentang perlawanan atas pengalihan fungsi hutan kota menjadi perumahan mewah (real estate). RII terlibat dalam diskusi dan unjuk rasa menentang pengalihan fungsi hutan kota menjadi perumahan mewah tersebut.

\section{Peristiwa Penggalian Gagasan}

RII menulis dan mengarang melalui tahapan maupun proses penemuan gagasan untuk menggarap karyanya. Banyak pihak yang terlibat dalam proses penulisan RII. RII tidak dapat mandiri dalam menuangkan gagasan dalam menulis. Terciptanya tulisan RII melibatkan beberapa orang dekatnya, pengetiknya, maupun para tamu dan teman-teman akrabnya.

Gagasan RII dalam mengarang bisa dikatagorikan atas beberapa hal sebagai berikut. 
50 | BAHASA DAN SENI, Tahun 46, Nomor 1, Februari 2018

Tabel 1. Pengelompokan Gagasan dalam Karya RII

\begin{tabular}{|c|c|c|c|}
\hline No & Gagasan & Karya Sastra & Keterangan \\
\hline \multirow[t]{2}{*}{1} & Pengalaman Pribadi & Batu Sandung & $\begin{array}{l}\text { Tokoh Irina berjuang secara mandiri } \\
\text { mengingat kaki lumpuh. }\end{array}$ \\
\hline & & Buah Tomat & $\begin{array}{l}\text { Pengalaman dua orang anak cacat yang } \\
\text { dirawat di ruang yang sama di sebuah rumah } \\
\text { sakit. Kedua anak itu sama-sama cacat yang } \\
\text { satu cacat kakinya dan satunya cacat tanganya. }\end{array}$ \\
\hline \multirow[t]{4}{*}{2} & Peristiwa & $\begin{array}{l}\text { Lemah Tanjung } \\
(2003)\end{array}$ & Hutan kota dijadikan real estate. \\
\hline & & Pecinan Kota & Kemajemukan etnis Tionghoa di Malang. \\
\hline & & Malang (2008) & Peristiwa lengsernya kekuasaan Orde Baru. \\
\hline & & Novel 1998 (2012) & \\
\hline \multirow[t]{2}{*}{3} & $\begin{array}{l}\text { Perenungan } \\
\text { (solilokui) }\end{array}$ & $\begin{array}{l}\text { Bilik Yang } \\
\text { Terkunci (2008) }\end{array}$ & $\begin{array}{l}\text { Cerita di masa anak-anak tentang puteri yang } \\
\text { cantik yang tidur selama } 100 \text { tahun karena } \\
\text { pengaruh ahli sihir. }\end{array}$ \\
\hline & & Bojoku (2008) & $\begin{array}{l}\text { Hasil perenungan RII ketika merasakan adanya } \\
\text { beban berat para homo maupun lesbi yang } \\
\text { selalu disingkirkan oleh masyarakat. RII } \\
\text { mempunyai pemikiran untuk memberikan satu } \\
\text { tawaran ketika setelah pulang dari United } \\
\text { States Of America (USA), yakni bentuk 'lesbi } \\
\text { yang sehat'. }\end{array}$ \\
\hline 4 & Bacaan & $\begin{array}{l}\text { Surat-surat Putri } \\
\text { (2009) } \\
\text { Dewi Sata Gandari } \\
\text { Ande-ande Lumut } \\
(2002)\end{array}$ & $\begin{array}{l}\text { Ide membuat cerita pendek dapat melalui } \\
\text { berbagai bacaan. Bacaan merupakan salah satu } \\
\text { sumber inspirasi dalam membuat cerpen } \\
\text { Bacaan dapat menambah wawasan dan } \\
\text { pengetahuan. Bacaan ini dapat dari berbagai } \\
\text { sumber seperti media massa, cetak maupun } \\
\text { elektronik. RII mencari ide dengan membaca } \\
\text { koran, majalah, mendengarkan radio, membaca } \\
\text { berita dari internet, menonton televisi, dsb. }\end{array}$ \\
\hline 5 & Diskusi & $\begin{array}{l}\text { Namanya Massa } \\
\text { (2001) }\end{array}$ & $\begin{array}{l}\text { RII menyukai berdialog, berdiskusi, dan } \\
\text { berdebat dengan siapapun tanpa memandang }\end{array}$ \\
\hline
\end{tabular}


Mansurudin, Epiphany of Ratna Indaswari Ibrahim | 51

\begin{tabular}{|c|c|c|c|}
\hline No & Gagasan & Karya Sastra & Keterangan \\
\hline & & $\begin{array}{l}\text { Cerpen Tujuh Belas } \\
\text { Tahun Lebih Empat } \\
\text { Bulan (2008) } \\
\text { Burung Bangau } \\
(2008)\end{array}$ & $\begin{array}{l}\text { kelas maupun golongan. Dengan berdiskusi } \\
\text { akan menambah wawasan bagi RII. Bahkan } \\
\text { tamu dan penggemar yang tak dikenal pun } \\
\text { akan diterima dengan baik. Hasil dari } \\
\text { berbicang bisa membuahkan gagasan dalam } \\
\text { membuat cerpen. }\end{array}$ \\
\hline 6 & Hal Sekitar RII & $\begin{array}{l}\text { Meong (2008) } \\
\text { Kura-kura (2004) } \\
\text { Warung (1995) } \\
\text { Boneka-bonekaku } \\
(2002)\end{array}$ & $\begin{array}{l}\text { Apapun yang ada di sekitar rumah bisa } \\
\text { dijadikan ide cerita oleh RII. RII } \\
\text { memanfaatkan betul apapun yang ada disekitar } \\
\text { rumah berupa mahluk selain manusia dijadikan } \\
\text { ide dalam membuat tulisan. }\end{array}$ \\
\hline
\end{tabular}

Ikan (2002) dsb.

Keunikan dan kecerdasan memanfaatkan situasi maupun mengambil sudut pandang, RII termasuk cerpenis dan sastrawan yang luar biasa. RII harus mendiktekan dan menyelaraskan emosi yang ada di dalam pikiran RII kepada pengetiknya.

RII berteman secara luas, antara lain dari. Kalangan akademis, politis, sastrawan, wong cilik, kaum difabel, bahkan teman-teman yang oleh masyarakat atau kelompok lain diangap ekstrim dan terbuang pun diterima sebagai teman RII. Kalangan HMI, PMII, GMNI dst. dianggap sebagai sumber informasi dan sumber inspirasi atas cerpen-cerpennya. RII berteman dengan PKI, PKS, PSI, PSK, dan juga PKK. Demikian kelakar dari RII yang sering ditirukan para sahabatnya.

Teman-teman maupun sahabat dijadikan alat observasi bagi RII. Kejadian-kejadian di luar yang tidak terjangkau oleh RII akan selalu ditanyakan kepada rekan-rekanya. Tidak jarang rekan, sahabat menganggap RII terlalu cerewet dan seolah menginterogasi rekan dan teman-temannya.

Semua orang di sekelilingnya diajak untuk diskusi seputar topik karya sastranya, namun kata akhir cerita tergantung pada RII sendiri. Rekan, teman, sahabat dan pengetik sangat dibutuhkan oleh RII untuk memberikan kritik dan masukan menghidupkan suasana cerpen.

Saran, kritik, dan masukan perbaikan akan ditampung dan diterima, namun kata akhir dalam memutuskan penyelesaian adalah hak prerogatif RII. RII mempunyai parameter tersendiri. Parameternya (a) menggerakkan hati perempuan, (b) membela kaum yang tertindas, (c) memperjuangkan keharmonisan alam semesta, dan (d) terkadang datar-datar saja, kurang membangun konflik, mengesankan ngudo roso (solilokui) dengan kehendak dan kemauan RII. Hampir pada setiap cerpennya Ratna melakukan gugatan-gugatan psikologis. Gugatan ini terutama diperuntukkan bagi diri sendiri (Darma, 2010).

RII dalam menyelesaikan cerpen tidak memasang target layaknya orang berbisnis atau berjualan. RII terkadang dapat menyelesaikan karyanya bisa satu atau dua jam, terkadang hitungan hari bahkan untuk novel bisa tahunan. Sebagai contoh dalam hitungan jam, cerpen Kanal (26/4/2009) dapat dikirim dan diterbitkan oleh Jawa Pos. Cerpen dengan hitungan 
hari adalah Rambutnya Juminten (1994), Burung Bangau (2008), Aminah di Suatu Hari (2004), Namanya Massa (1995), Kali Bakar, dsb. Karya sastra yang menjadi hitungan tahunan adalah Lemah Tanjung (2004), Pecinan Kota Malang (2008), dan 1998 (2012).

Lamanya membuat cerpen, novelet, dan novel karena berbagai hal, mulai banyaknya tamu yang datang dan pergi, kesibukan sebagai tokoh LSM, menghadiri undangan pembicara antarkampus, dan juga terkadang menunggu jawaban dari teman-teman, sahabat atas macetnya penyelesaian karyanya. RII membutuhkan jawaban atas observasi, data lanjutan, informasi bahkan harus membaca beberapa buku guna mendukung gagasannya dalam karya. Misalnya data tambahan dari rekan RII adalah mengenai masalah latar suatu tempat karena RII tidak dapat bebas bergerak, maka membutuhkan informasi tambah mengenai kondisi latar-fisik. Novel Lemah Tanjung (2004), Pecinan Kota Malang (2008) dan 1998 (2012) merupakan karya yang membutuhkan waktu yang panjang. Untuk novel 1998 khusus diterbitkan setelah RII meninggal dunia.

\section{Peristiwa Pengungkapan Gagasan}

Wujud atau bentuk gagasan RII dalam karya sastranya berbagai macam. Gagasan maupun kerangka cerita yang masih ada di dalam bayang-bayang pikiran RII perlu diwujudkan dalam cerita pendek, novelet atau novel.

Berikut Tabel bentuk gagasan RII dalam membuat karya sastra baik cerpen, novelet, maupun novel.

Tabel 2. Bentuk Gagasan RII dalam Membuat Karya

\begin{tabular}{|c|c|c|c|c|c|}
\hline No. & $\begin{array}{c}\text { Bentuk } \\
\text { Gagasan }\end{array}$ & & Judul & Uraian & Hikmah \\
\hline 1 & $\begin{array}{l}\text { Tokoh dalam } \\
\text { Mitos }\end{array}$ & $\begin{array}{l}0 \\
0\end{array}$ & $\begin{array}{l}\text { Ande-ande Lumut } \\
\text { Drupadi } \\
\text { Dewi Setyawati. } \\
\text { Bilik yang } \\
\text { Terkunci } \\
\text { Busana Dayang } \\
\text { Sumbi }\end{array}$ & $\begin{array}{l}\text { O Kisah Panji } \\
\text { Asmarabangun } \\
\text { mencari istrinya } \\
\text { Sekartaji } \\
\text { o Dewi dalam } \\
\text { pewayangan } \\
\text { yang taat Suami } \\
\text { o Cerita Putri } \\
\text { Salju } \\
\text { o Cerita } \\
\text { Sangkuriang } \\
\text { dan ibunya } \\
\text { Dalang Sumbi }\end{array}$ & $\begin{array}{ll}\text { O } & \text { Keteraniyaaan wong cilik } \\
\circ & \text { Kehidupan rumah tangga } \\
\text { harus dilandasi } \\
\text { kepercayaan } \\
\text { kesetiaan } \\
\text { Seseorang hidup harus } \\
\text { mempunyai mimpi dan } \\
\text { tak berputus asa } \\
\text { Inses merupakan larangan } \\
\text { agama dan tak baik untuk } \\
\text { genetika }\end{array}$ \\
\hline 2 & $\begin{array}{l}\text { Cerita dalam } \\
\text { Sejarah }\end{array}$ & O & $\begin{array}{l}\text { Salma yang } \\
\text { Terkasih } \\
\text { Good by Erick }\end{array}$ & $\begin{array}{l}\text { O Cerita diilhami } \\
\text { oleh Nabi } \\
\text { Yusuf dan } \\
\text { Zulaikah } \\
\text { o Cerita pisahnya } \\
\text { Propinsi Timor } \\
\text { Timur dari } \\
\text { Indonesia }\end{array}$ & $\begin{array}{l}\text { Cinta ada batas dan } \\
\text { landasanya } \\
\text { Nasioanlisme tidak hanya } \\
\text { diukur pada tingkat } \\
\text { kemakmuran }\end{array}$ \\
\hline 3 & $\begin{array}{l}\text { Cerita dari } \\
\text { Lingkungan } \\
\text { Sekitar }\end{array}$ & $\begin{array}{l}0 \\
0 \\
0\end{array}$ & $\begin{array}{l}\text { Lemah Tanjung } \\
1988 \\
\text { Tujuh Belas }\end{array}$ & $\begin{array}{l}\text { o Perlawanan } \\
\text { Lemah Tanjung } \\
\text { o Perlawanan }\end{array}$ & $\begin{array}{l}\text { Melawan (melalui sastra) } \\
\text { merupakan upaya dan }\end{array}$ \\
\hline
\end{tabular}


Mansurudin, Epiphany of Ratna Indaswari Ibrahim | 53

\begin{tabular}{|c|c|c|c|c|c|}
\hline No. & $\begin{array}{c}\text { Bentuk } \\
\text { Gagasan }\end{array}$ & & Judul & Uraian & Hikmah \\
\hline & & ○ & $\begin{array}{l}\text { Tahun Lebih } \\
\text { Empat Bulan } \\
\text { Tetangga Sebelah } \\
\text { Rumah } \\
\text { Aminah di Suatu } \\
\text { Hari } \\
\text { Kali Bakar }\end{array}$ & $\begin{array}{l}\text { Rezim Otoriter } \\
\text { (Orba) } \\
\text { o Sindikat } \\
\text { Pengemis } \\
\text { o Sikap } \\
\text { Individualis } \\
\text { masyarakat kota } \\
\text { o Kecantikan } \\
\text { inner beauty } \\
\text { o Anarkhis }\end{array}$ & $\begin{array}{l}\text { senjata masyarakat yang } \\
\text { kalah }\end{array}$ \\
\hline 4 & $\begin{array}{l}\text { Cerita dari } \\
\text { Pengalaman } \\
\text { Sendiri }\end{array}$ & o & $\begin{array}{l}\text { Bilik Yang } \\
\text { Terkunci } \\
\text { Batu Sandung }\end{array}$ & $\begin{array}{l}\text { O Obsesi } \\
\text { perempuan } \\
\text { cantik } \\
\text { O Kemandirian } \\
\text { perempuan } \\
\text { difabel }\end{array}$ & $\begin{array}{l}\text { Perjuangan sebagai } \\
\text { difabel bukan disabel }\end{array}$ \\
\hline
\end{tabular}

\section{Peristiwa Pematangan Gagasan}

Gagasan yang telah terangkum hasil dari berbagai macam, perlu dimatangkan dengan konkrit. Sebagai pengarang yang mempunyai ketergantungan terhadap pengetik, RII berusaha secepat dan sesempat mungkin untuk segera merealisasikan dengan mematangkan gagasan agar menjadi cerita karya sastra yang utuh dan tuntas.

"Waktu itu saya belum tergerak. Proses kreatif saya, ya cerita-cerita yang saya dengar, walau mungkin pada saat itu tidak menggerakkan hati saya, tapi sudah menjadiembrio-embrio yang suatu saat bakal menjadi tema sentral. Pengalaman dari mendengar dan membaca itu penting, karena seperti saya bilang tadi, saya ini sastrawan lisan yang tidak bisa mobile," begitu Ratna mengaku.

RII melakukan aktivitasnya dibantu beberapa asistennya, salah satunya Rini. RII sebagai juru cerita lisan-tidak tertulis. Rini aktif mengikuti sejak RII sejak berusia 13 tahun. Tugas Rini adalah mengetik, apa yang didiktekan oleh RII. Proses kreatifnya RII juga tergantung pada pengetiknya. RII baru bisa menulis kalau Rini suasana dan kesiapannya (mood-nya) dalam mengetikkan karya RII. Jika pengetiknya (Rini) kurang siap dan mood-nya kurang bagus, maka karya RII hanya sekedar karya lisan yang dapat dinikmati oleh pikiran RII atau pendegarnya yang mau mendengar.

Peristiwa pematangan gagasan RII dalam berkarya melalui proses berupa: (i) mendiktekan gagasan dalam tulisan, (ii) mencetak tulisan, (iii) membaca dan mengedit tulisan, dan (iv) mempublikasikan tulisan.

Setelah dicetak, dibaca, dinalisis, diedit, dikoreksi, kemudian diketik lagi atas hasil editan, maka akhir dari proses penulisannya adalah dikirim kepada media massa. Hasil kiriman karya RII ada yang diterima media massa, dikembalikan, tercecer, dan dibuat antologi cerpen.

Peristiwa penting kehidupan feminis RII dalam mengarang dan menulis, berupa peristiwa penggalian gagasan, proses pengungkapan gagasan, dan proses pematangan gagasan. Isi maupun gagasan RII dalam mengarang adalah tentang advokasi dan perjuangan atas hak-hak perempuan. Di samping itu, dalam kesehariannya banyak peristiwa 
penting yang dilaluinya sebagai pengarang, yakni (i) pemberdayaan pengetik perempuan, (ii) pemberdayaan perempuan sebagai sumber inspirasi (perempuan di penjara), (iii) konsultan sastra, dan (iv) sangat majemuk dalam menampung dari berbagai macam elemen ideologi.

\section{Epifani Kedifabelan RII Menjadi Pengarang}

Kenikmatan mengarang RII dapat dirasakan dari karya dan kehidupan pribadinya. RII mampu mendidik, mengajarkan, membimbing, menggerakkan dan mampu menginspirasi masyarakat baik difabel maupun manusia sempurna. RII mampu menyelami, tumbuh dengan idenya sendiri, tidak memaksakan satu pikiran sesuai dengan pikiran dirinya.

Menulis karya sastra mempunyai kenikmatan tersendiri yang tidak dapat dimiliki oleh ahli hukum, psikologi maupun akunting. Kenikmatan menulis memberikan kepuasan batin, kepuasan hasrat, dan merasakan puncak kenikmatan intelektual yang luar biasa. Bekerja sebagai pengarang bagi RII dapat merasa berbagi terhadap sesama dan meninggalkan kebaikan kepada masyarakat. Jasa-jasanya dikenang publik karena kesederhanaan, perjuangan terhadap perempuan, dan kehumanisan.

Cerpen, novelet, dan novel akan selalu dikenang sebagai warisan sastrawan dari Malang dengan segala keterbatasannya. Cerpen, novelet dan novel RII bukan hanya sekedar sebagai pelipur lara maupun berindah-indah dalam kata. Akan tetapi, karya sastra RII merupakan puncak dari kenikmatan berjuang, pantang menyerah melawan kebenaran dan mencari keadilan.

Adapun nilai-nilai kandungan kenikmatan mengarang ditemukan beberapa hal sebagai berikut. Pertama, memelihara anak angkat sebagai anak sendiri. RII mengadopsi Rohadi sebagai anak angkatnya. Rohadi diangkat, dididik, dan dibimbing oleh RII sampai dapat mandiri menulis dan bekerja dalam penerbitan. Sebelumnya Rohadi tidak mengerti, mengetahui tentang dunia mengarang maupun dunia penerbitan.

Kedua, mempersatukan beberapa orang dari berbagi bendera dan golongan dalam satu wadah, yaitu Forum Pelangi. Demikian pula RII menjadi pimpinan kaum difabel seluruh Malang. Atas pimpinannya, RII dapat menyalurkan aspirasi, keinginan maupun sesuatu yang menjadi problematika kaum difabel kepada pemerintah.

Ketiga, peninggalan dalam dunia edukasi adalah buku Pelajaran Mengarang. Buku tersebut merupakan amal jariyah kepada siapapun untuk dibaca dan dipelajari agar dapat mengarang. Intinya buku tersebut berisi kiat-kiat seseorang ketika mengarang cerita fiksi. Buku tersebut memberikan inspirasi, maupun pelatihan terhadap perempuan-perempuan dalam berkarya. RII juga menerima konsultasi apresiasi sastra (cerpen dan puisi). Banyak penggemar yang mengirimkan puisi dan cerpennya untuk dikomentari RII.

Keempat, memberikan bentuk penyadaran pada cerpenis lain. Contohnya dalam cerpen Namanya Massa (2001) terjadi polemik antara RII dengan tokoh Massa (Jenar MahesaAyuJMA). Dalam polemik tersebut ada sedikit penyadaran pada diri JMA dengan bertanya pada diri sendiri, yakni "Sebejat itukah diriku?" (surat untuk RII dari JMA, 3/14/2001).

Kenikmatan mengarang RII dapat dimanifestasikan dalam tiga hal utama, yakni (a) tentang advokasi dan perjuangan atas hak-hak perempuan, (b) penginspirasi para penyandang cacat, (c) perjuangan terhadap lingkungan hidup.

Kedifabelan sebagai pencerahan, pergeseran paradigma, tansformasi nilai kehidupan RII yang hakiki dan permanen. Peristiwa yang dialami RII sebagai 'kuantum perubahan' dala perjalanan kehidupanya. Istilah kuantum perubahan merupakan konsep ephipany 
Miller dan C'de Baca (McDonald, 2005). Kuantum perubahan mendasar RII adalah menjadi pengarang dan penulis karya sastra. Pengarang karya sastra merupakan momentum ephipany RII (lihat Denzin, 1989: 71) dalam menghadapi kehidupan nyata. Ephipany RII memberikan titik tolak pergeseran paradigma dalan memahami arti dan makna kehidupan.

Banyak pandangan yang menyebut bahwa tradisi lisan terbelakang daripada tradisi tulis. Hal ini karena tradisi lisan memang tidak terbiasa mengungkapkan gagasan dalam urutan linier dan analitis yang biasa dibangun dengan bantuan teks (Ong, 2013).

\section{PENUTUP}

Proses RII menjadi pengarang merupakan hal yang unik dan langka di dunia tulis menulis. Hal ini karena RII sendiri menyebut sebagai sastrawan lisan. Apa yang menjadi tema-tema karyanya tidak diketik sendiri, namun dilisankan kepada para pengetiknya. Hal dilakukan RII seolah-olah merupakan sebuah tradisi lisan. Padahal kerangka RII dalam membuat cerpen, novelet, dan novel merupakan pengorganisasian yang kompleks, cerdas, dan indah yang muncul dalam proses kerja memori lisan. Jadi tidak benar jika ada pandangan yang menempatkan tradisi lisan lebih terbelakang daripada tradisi tulisan.

Ephipany RII sebagai pengarang karya sastra dapat dimanifestasikan dalam kehumanisannya berupa sikap nyata yang membela kaum lemah dan menampung segala lapisan masyarakat tanpa adanya perbedaan ideologi, golongan maupun suku. Dalam ephipany kefeminisan RII memimpikan perempuan-perempuan dapat berdaya, sederajat, setara, dan menjadi subjek yang utuh. Selanjutnya epifani dari sisi kedifabelan, RII mampu berjuang dan mengaktuaslissikan serta menjadi sumber inspirasi bagi kaumnya dan tidak mau diperlakukan sebagai manusia disabel.

Disarankan kepada pemerintah selayaknya lebih memperhatikan kaum difabel melalui pendidikan maupun latihan, agar kaum difabel dapat mengaktualisasikan diri berdasarkan bakat dan minatnya. Kaum difabelitas memerlukan kurikulum bagi perjalanan pendidikannya. Perlu lebih dikonkretkan dan diwujudkan segera mengingat persentase difabelitas cukup signifikan setiap tahunya. Oleh karena itu, pemerintah dapat memprioritaskan pembangunan infrastuktur dan kurikulum terkait akses untuk kaum difabel.

\section{DAFTAR RUJUKAN}

Arcana, Putu Fajar. 2011. "Sang Pemberani itu Pergi”. Kompas, 3 April.

Creswell, J. W. 1998. Qualitative Inquiry and Research Design: Choosing among five Approaches. Thousand Oaks, CA: Sage Publications Inc.

Creswell, J. W. 2007. Qualitative Inquiry \& Reserach Design. California: Sage Public.

Darma, Budi. 1995. Harmonium. Yogyakarta: Pustaka Pelajar.

Darma, Budi. 2015. "Menu Sastra Serba Instan". Kompas, Minggu, 12 April.h.12.

Denzin, N. K. 1989. Interpretive Biography. Newbury Park, CA: Sage Publications.

Denzin, Norman K. \& Yvonna S. Lincoln. 2000. Handbook of Qualitative Research. California: Sage Publication, Inc.

Eneste, Pamusuk (Ed). 2009. Proses Kreatif: Mengapa dan Bagaimana Saya Mengarang I. Jakarta : KPG (Kepustakaan Populer Gramedia).

Fay, Brian. 1998. Filsafat Ilmu Sosial Kontemporer. Diterjemahkan oleh M. Muhith. 2002. Yogyakarta: Jendela. 
Freud, Sigmund. 1900. The Interpretation of Dreams Standard Edition, 4\&5.London: Hogarth Press.

McDonald, Mattew G. 2005. Epiphanies: An Existential Philosophical And Psychological Inquiry. Graduate School of the University of Technology, Sydney: Australia.

Saryono, Djoko. 2009. Dasar Apresiasi Sastra. Yogyakarta: Elmatera Publishing.

Saryono, Djoko. 2014. Hazim Amir: Sang Humanis Transendental. Malang: Esai tidak diterbitkan.

Saryono, Djoko. 2014. Ratna, Sastra, dan Kemanusiaan. Pidato Orasi Ilmiah dalam rangka Hari Kebangkitan Nasional 20 Mei.

Teew, A. 1984. Sastra dan Ilmu Sastra.Jakarta: Pustaka Jaya 